\title{
From weeds spring eternal flowers
}

\author{
Mondher Bouzayen and Jean-Claude Pech
}

In 1993, the first known hormone receptor in plants was isolated, thanks to a molecular genetics approach using mutants of the brassica Arabidopsis thaliana. The isolated receptor recognizes the plant hormone ethylene, which plays a critical role in a myriad of plant processes, including senescence. As the survival of perishable crops depends largely on the timing and rate of senescence, isolation of the gene encoding the ethylene receptor is of particular interest-extending the vase life of tiny Arabidopsis flowers may not be of commercial import, but the introduction of this trait into horticultural varieties is of tremendous significance. In this issue, Harry Klee and colleagues ${ }^{2}$ report the creation of ethylene-insensitive transgenic petunias that exhibit extended survival both on and off the plant-the first manipulation of the ethylene receptor in a crop of commercial importance.

The international trade in cut flowers and potted plants is of considerable economic value for both developed and developing countries. The market for ornamentals is lucrative and offers encouraging prospects for substantial development in the near future. However, senescence, a common fate for both plants and animals, remains a considerable block. The relatively short life of cut flowers and potted flowering plants reduces their commercial value and considerably restricts the range of species that are available in horticultural production.

For many flowers (e.g., carnations, petunias, orchids, and hibiscus), senescence is the result of a cascade of gene transcription triggered by the plant hormone ethylene. Classi-

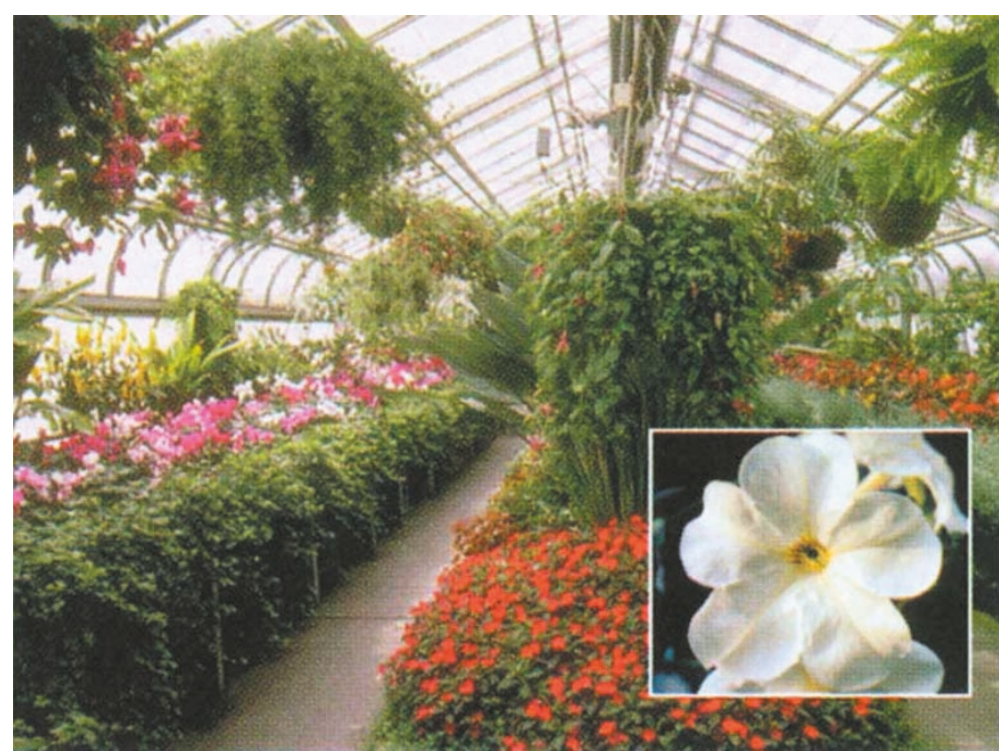

Figure 1. Horticulture could reap significant benefit from ethyleneinsensitive petunias (inset) and other commercial varieties. cals that prevent either ethylene synthesis (aminoethoxyvinyl glycine and amino oxyacetic acid) or its action [silver thiosulfate

Klee et al. report the creation of ethylene-insensitive transgenic petunias that exhibit extended survival both on and off the plantthe first manipulation of the ethylene receptor in a crop of commercial importance.

(STS), 2,5-norbornadiene, and 1-methylcyclopropene] has been a major means for controlling flower senescence. Most commonly, the ethylene action inhibitor STS is postharvest storage of perishable crops through the genetic manipulation of ethylene biosynthesis. Transgenic tomato ${ }^{5}$ and melon $^{6}$ with reduced levels of ethylene biosynthesis and inhibited ripening have been generated, demonstrating the efficiency of molecular techniques. More recently, genes encoding the two key enzymes of the ethylene biosynthetic pathway [1-aminocyclopropane-1-carboxylate (ACC) synthase and ACC oxidase] have been silenced in ethylene-sensitive flowers, resulting in significant extension of postharvest life.

Although this is a major advance, such transgenic flowers remain capable of sensing and responding to ethylene and therefore exhibit the same decay as untransformed wild-type flowers when in contact with exogenous sources of ethylene (i.e., other ethylene-producing flowers, fruits, hydrocarbon combustion gases). This greatly restricts the potential for commercial development, and there is little chance that these flowers will be released to the market. In contrast, transgenic flowers mutated in the ethylene receptor do not have this shortcoming and would be expected to be of real commercial interest. In addition, the public acceptability problems associated with transgenic foods should not be applicable to ornamental flowers because they are generally not intended for human consumption.

The propects offered for extending the life of potted or cut ornamentals through the manipulation of ethylene perception originated from the study of the model plant Arabidopsis thaliana. Doubtless, more examples of commercial cal breeding has succeeded in generating only a few varieties exhibiting extended postharvest life. As a result, the use of chemi-

Mondher Bouzayen is an assistant professor of plant molecular biology and Jean-Claude Pech is a professor of postharvest physiology in the Ecole Nationale Supérieure Agronomique, 145, avenue de Muret, 31076 Toulouse Cedex, France (bouzayen@flora.ensat.fr; pech@flora.ensat.fr). used to counteract the harmful effects of ethylene ${ }^{3}$; however, the continued use of STS on a large scale is in doubt because of increasing public concern regarding the environmental toxicity of heavy metals. Indeed, processes that will eventually lead to the banning of STS are under way in many countries. The ethylene antagonist 1-methylcyclopropene (1-MCP) may represent an interesting alternative to $\mathrm{STS}^{4}$.

In recent years, there has been a dramatic change in the prospects for improved application will eventuate from basic research into Arabidopsis mutants.

1. Chang, C., Kwok, S., Bleecker, A., and Meyerowitz, E. 1993. Science 262:539-544.

2. Wikinson, J.Q. et al. 1997. Nature Biotechnology 15:444-447.

3. Veen, H. 1983. Sciencia Horticulturae 20:211-224.

4. Serek, M. Sisler, E.C., and Reid, M.S. 1994. Plant Growth Regul. 16:93-97.

5. Hamitton, A.J., Lycett, G.W., and Grierson, D. 1990. Nature 346:284-287.

6. Ayub, R.A. et al. 1996. Nature Biotechnology 14:862-866. 